\title{
A Influência do País de Origem no Desempenho das Empresas
}

\author{
Luiz Artur Ledur Brito \\ Flávio Carvalho de Vasconcelos
}

\section{Resumo}

A dispersão dos resultados de empresas norte americanas tem sido analisada, na área de estratégia, com a técnica de componentes de variância. Os efeitos da empresa têm aparecido como os mais relevantes, seguidos dos efeitos do ramo de negócios, e dos específicos ao ano. Este trabalho amplia esta linha de estudos ao considerar uma amostra de empresas de 78 países. Um novo tipo de efeito foi criado: o efeito país refletindo a influência do país no desempenho. Uma amostra da Compustat Global de 12.592 empresas, 60.092 observações (1997/2001) foi usada. Os resultados indicam que o efeito país existe e é relevante. A composição da variância varia em função do setor econômico considerado. Na Mineração, Construção e Transportes o efeito país total (soma do efeito país direto e da sua interação com o ramo de negócios) é o mais relevante superando o efeito da empresa individual. Nos demais setores ele é o segundo principal efeito e apenas no setor de serviços o efeito país não aparece de forma relevante. Os resultados evidenciam, de forma empírica, o efeito do contexto institucional no desempenho e indicam que a transposição de teorias e conclusões desenvolvidas em outros contextos pode necessitar de adaptações relevantes.

Palavras-chave: performance; estratégia; componentes de variância; países.

\begin{abstract}
Performance dispersion of North American firms has been analyzed, in the strategy field, using the variance components technique. Firm effects have been identified as the most relevant ones, followed by industry and year effects. This research expands this line of study considering a sample of firms from 78 different countries. A new type of effect was created: the country effect reflecting the influence of country of origin in performance. A Compustat global sample of 12,592 firms with 60,092 observations (1997/2001) was used. Results indicate that country effects do exist and are relevant. Variance composition varies by economic sector. In Mining, Construction and Transport, total country effect (adding pure country effect to country $\mathrm{x}$ industry interaction) is the largest variance component, being more important than firm effects. In most remaining economic sectors it is the second most important effect and only in Services it does not show up. Results demonstrate empirical evidence of the influence of the institutional context in performance and indicate that transposition of theories and conclusions derived in particular contexts may need relevant adaptations to be applied to different countries and settings.
\end{abstract}

Key words: performance; strategy; variance components; country. 


\section{INTRODUÇÃO}

As empresas são diferentes. As fontes e a importância das diferenças entre as empresas e setores oferecem campo fértil para estudos de economia e estratégia (CARROLL, 1993; NELSON, 1991). O desempenho das empresas também varia. Embora as tentativas de explicar diferenças em desempenho tenham sido um dos temas mais persistentemente estudados em organizações, este não é desafio simples e enfrenta muitas dificuldades (MARCH; SUTTON, 1997).

A técnica de componentes da variância pode oferecer uma visão interessante na estimativa das diversas classes de fatores ou tipos de efeitos que determinam o desempenho das empresas. Após os estudos originais de Schmalensee (1985) e Rumelt (1991), diversos autores estudaram a estrutura da variância do desempenho, decompondo-o em efeitos da empresa, corporativo, ramo de negócios ou setor industrial e de ano (BRUSH; BROMILEY; HENDRICKX, 1999; CHANG; SINGH, 2000; HAWAWINI; SUBRAMANIAN; VERDIN, 2003; MAURI; MICHAELS, 1998; MCGAHAN, 1999; MCGAHAN; PORTER, 1997, 2002; MCNAMARA; VAALER; DEVERS, 2003; ROQUEBERT; PHILLIPS; WESTFALL, 1996).

A grande maioria desses estudos indicou que o efeito da empresa individual é o componente dominante da variância explicada e tem influência claramente maior na explicação da dispersão do desempenho do que o efeito indústria ou o fato de pertencer a determinado ramo de negócios. Isto alimentou o debate, na área de estratégia, entre a abordagem derivada da organização industrial e a visão baseada em recursos. A importância do efeito corporativo tem tido resultados mais contraditórios e parece ser sensível à amostra e ao período analisado. Os efeitos do ano foram, normalmente, muito pequenos ou não-existentes.

Todos os estudos previamente citados foram conduzidos com dados dos EUA e descrevem o ambiente de negócios da economia americana. Um dos poucos, talvez o único artigo já publicado sobre o assunto, analisando a variância de desempenho de empresas fora dos EUA, foi feito por Claver, Molina e Tarí (2002), cujos resultados mostraram uma composição de variância do desempenho semelhante.

Já que a grande maioria dos estudos foi realizada com dados dos EUA, a localização, interpretada como o país onde a empresa opera, nunca foi considerada como fonte de heterogeneidade neste tipo de pesquisa. A teoria econômica e da estratégia, contudo, reconhecem que a localização é um dos 
mais importantes determinantes do desempenho das empresas. Na tradição de pesquisas econômicas, este aspecto pode ser observado nos trabalhos do economista clássico David Ricardo ([1817] 1996), na noção das vantagens comparativas. No campo da estratégia, o trabalho de Michael Porter (1990, 1998, 2000) sobre a vantagem competitiva das nações e dos aglomerados industriais certamente relaciona o desempenho à localização.

Este artigo tenta contribuir com o esforço de ampliar o conhecimento atual sobre a composição da variância do desempenho das empresas, cobrindo o aspecto localização e explorando o ambiente de negócios em outros países. O primeiro objetivo é detectar a influência do país na heterogeneidade do desempenho das empresas. Com base em pesquisas anteriores sobre componentes de variância, novo tipo de efeito foi isolado. O efeito país reflete a influência da nacionalidade no desempenho das empresas. Ele representa a influência de fatores no ambiente de negócios do país que afetam o desempenho das empresas de maneira positiva e negativa, como graves recessões ou períodos de extrema prosperidade e crescimento. Em outras palavras, o primeiro objetivo específico é responder a esta pergunta: O país importa? O segundo objetivo deste artigo é responder à próxima pergunta que, logicamente, se impõe: Quanto importa o país? Isto será feito pela quantificação da magnitude deste efeito em diferentes setores da economia.

O efeito país, contudo, pode não ser independente dos outros efeitos. Os fatores relacionados ao país podem afetar alguns ramos de negócios específicos de maneira diferente e serem neutros em outros. O terceiro objetivo é identificar e quantificar a interação país e ramo de negócios.

Finalmente, este artigo estima a composição da variância do desempenho em empresas de 78 países diferentes. O quarto objetivo é, então, avaliar a composição da variância do desempenho em ambiente verdadeiramente internacional, expandindo o que foi feito em estudos anteriores, que usavam principalmente dados dos EUA. A base de dados globais COMPUSTAT foi utilizada como fonte de dados. Foi selecionado um subconjunto desta base que cobriu resultados de 12.592 empresas entre 1997 e 2001, operando em 78 países, com um total de 60.092 observações.

Tendo explicado o que este artigo pretende desenvolver, é conveniente deixar claro o que ele não intenta. A abordagem da técnica dos componentes de variância é descritiva, ao invés de normativa; alguns a denominam de ateórica (MCGAHAN; PORTER, 1997; RUMELT, 1991). A identificação e a quantificação de certo componente não permitem a conclusão sobre causa e efeito. Abordagens de pesquisa diferentes seriam necessárias para identificar quais aspectos do país influenciam o desempenho de maneira positiva ou negativa. 
Compreender e mapear a distribuição do desempenho é, contudo, útil. Se grande proporção da variância é atribuível a certo fator, é lógico que aspectos específicos abrangidos por tal fator são relevantes e devem ser estudados; e o oposto é verdadeiro.

Inicialmente, estudos anteriores sobre os componentes da variância do desempenho e da relevância do aspecto localização são discutidos. O método de componentes da variância, a escolha da medida do desempenho, e as características da base de dados são descritos na seção sobre método e dados. Os resultados e sua discussão são apresentados em seguida e uma seção sobre conclusões ressalta as principais contribuições do trabalho. Uma seção final propõe possíveis ligações entre esta linha de pesquisa em estratégia com os novos campos de economia institucional e desenvolvimento econômico.

\section{Revendo Estudos Anteriores sobre Componentes da Variância}

Schmalensee (1985) publicou um artigo seminal, usando dados da Federal Trade Commission (FTC), ano de 1975, analisando os resultados em 1.775 unidades de negócios. O efeito ramo de negócios foi responsável por 19-20\% da variância total. Um dos pontos importantes da pesquisa consistia, contudo, no que não foi explicado, ao invés do que foi revelado. Reconhecendo que o modelo não poderia explicar 80\% da variância da rentabilidade das empresas, o autor menciona: “Apesar das diferenças do ramo de negócios importarem, elas claramente não são tudo o que importa” (SCHMALENSEE, 1985, p. 350, tradução nossa).

Rumelt (1991) estendeu o trabalho original de Schmalensee (1985), usando a mesma base de dados FTC, mas valendo-se de quatro anos em lugar de um. No total, 6.932 observações foram consideradas. Com quatro anos de resultados foi possível identificar a parte da variância total associada com a unidade de negócios individual, e a variância associada com a interação ano x ramo de negócios, separando as influências fixas e transitórias do ramo de negócios. O modelo foi capaz de explicar 63.33\% da variância total. O ramo de negócios foi capaz de explicar $16.2 \%$ da variância total, sendo que os efeitos permanentes associados ao ramo de negócios foram de apenas $8.3 \%$ deste valor. O restante foi atribuído à interação ano x ramo de negócios representando, pois, uma influência transiente do ramo no desempenho. Os efeitos da empresa, ou fatores persistentes, associados com cada unidade de negócios individual, responderam por $46.4 \%$ da variância total.

Apesar de esses dois artigos oferecerem descobertas consistentes, eles foram 
usados para justificar correntes teóricas diferentes. O trabalho de Schmalensee (1985) foi usado para apoiar a análise estratégica baseada na estrutura do setor (MONTGOMERY; PORTER, 1991), enquanto os resultados de Rumelt (1991) foram usados para questionar esta visão, uma vez que ele achou grande e significativa influência dos fatores permanentes associados com as unidades de negócios. Isto enfatizava a importância das abordagens baseadas em recursos (ROQUEBERT; PHILLIPS; WESTFALL, 1996).

Roquebert, Phillips e Westfall (1996) publicaram um estudo semelhante, usando a base de dados COMPUSTAT. Os dados se referiam ao período de 1985 a 1991, usando 16.596 observações. Os resultados foram semelhantes aos dos dois estudos anteriores, com uma notável exceção, o efeito corporativo. Eles acharam um efeito corporativo significativo que explicava $17.9 \%$ da variância total. O modelo foi capaz de explicar 68.0\% da variância total deixando 32\% sem explicação.

McGahan e Porter (1997) publicaram amplo trabalho, baseado em dados COMPUSTAT, entre 1981 e 1994, com 72.742 observações. Enquanto os estudos anteriores usaram apenas empresas manufatureiras, McGahan e Porter (1997) analisaram também outros setores econômicos, além da manufatura como a agricultura, atacado, transporte, serviços, hotelaria e lazer. Quando apenas os resultados do setor econômico manufatura deste estudo são comparados aos estudos anteriores, eles são, novamente, consistentes, apesar da diferente amostra e da metodologia modificada. O maior componente da variância estava associado com a unidade de negócios e correspondia a 35.45\% do total. O ramo de negócios respondeu por $10.81 \%$ da variância, e o efeito ano por $2.34 \%$. Os mesmos dados foram analisados com o emprego do modelo original de Rumelt (1991), fornecendo resultados semelhantes.

Em outros setores econômicos, como mineração, agricultura, atacado, transportes, serviços, hotelaria e lazer, a composição da variância foi significativamente diferente da manufatura e a influência do ramo de negócios foi muito maior. No agregado de todos os setores econômicos, o ramo de negócios respondeu por mais de 17\% de variância (MCGAHAN; PORTER, 1997).

Apesar das discrepâncias relacionadas com o efeito corporativo nesta linha de pesquisa, existem notáveis coincidências nos outros componentes da variância, considerando-se as diferenças nos dados e métodos empregados. O maior componente da variância sempre foi o efeito associado às características individuais das unidades de negócios, correspondendo a um valor entre um terço e metade da variância total. O ramo de negócios também é um efeito importante, mas sua influência está, de forma geral, entre 10 e $20 \%$ da variância total, e parte disto é devido à interação com o ano. 
Diversos outros autores também exploraram o tema, usando metodologias e abordagens diferentes, para chegar a conclusões consistentes com o sumário anterior. Wernerfelt e Montgomery (1988) usaram o q de Tobin para medir o desempenho. Hansen e Wernerfelt (1989) decompuseram o lucro em seus componentes econômicos e organizacionais. Powell (1996) usou uma metodologia de levantamento e entrevistas, confirmando que o efeito ramo de negócios poderia explicar algo em torno de 20\% do total da variância. Mauri e Michaels (1998) exploraram a influência dos diversos tipos de efeito nas estratégias adotadas pelas unidades de negócios. McGahan (1999) explorou o uso de diferentes medidas de desempenho: q de Tobin; lucratividade contábil tradicional; e uma medida híbrida, retorno sobre o valor de reposição dos ativos. McGahan e Porter (1999) estudaram o problema da persistência de diversos efeitos. Hawawini, Subramanian e Verdin (2003) também exploraram outras medidas de desempenho financeiro e o efeito da composição da amostra. McNamara, Vaaler e Devers (2003) usaram janelas móveis de quatro anos para observar as mudanças na composição da variância, valendo-se dos dados do Compustat dos EUA entre 1978 e 1997. Todos esses estudos utilizaram dados dos EUA. Análises semelhantes com dados de outros países são muito limitadas. Claver, Molina e Tari (2002) estudaram empresas espanholas, encontrando resultados semelhantes. Todas as análises incluíam efeitos da empresa individual, ramo de negócios, corporativo e de ano apenas. Estudos entre diferentes países nunca foram realizados com esta abordagem. A localização não foi considerada como fator de influência sobre a variância do desempenho.

\section{Localização e Desempenho}

A geografia tem sido ligada ao desempenho econômico das empresas desde os primeiros dias do pensamento econômico. Adam Smith ([1776] 2000) introduziu a idéia da vantagem absoluta, na qual uma região com custos menores poderia dominar o mercado, exportando para outros. Ricardo ([1817] 1996) aprofundou a questão com a noção da vantagem comparativa. O comércio exterior é baseado na existência de desigualdades dos fatores de produção entre os países. Países com abundância de certos fatores de produção poderiam explorar as vantagens comparativas, produzindo bens que demandavam uso intenso desses fatores. Os países com baixos custos de mão de obra deveriam ter uma vantagem comparativa na produção de bens que necessitassem de grande intensidade de mão de obra no processo produtivo.

Krugman (1994) reavaliou os efeitos das economias externas, relacionadas a uma localização geográfica específica, sobre a posição competitiva das empresas, 
chegando à conclusão de que a geografia é importante, e que a economia sem fronteiras ainda não existe. O aumento do grau de integração da economia moderna, a redução dos custos de transportes e o aumento das trocas de informações poderiam indicar que estamos aproximando-nos de um mundo sem fronteiras, habitado por empresas globais, até mesmo desnacionalizadas. A análise de Krugman (1994) demonstrou que a localização ainda é importante, não apenas devido às vantagens comparativas, mas também devido ao aumento da competitividade decorrente de vantagens desenvolvidas. Estas vantagens desenvolvidas foram previstas por Marshall (1952) e estão relacionadas, tanto com a aglomeração em larga escala de vários ramos de negócios em certas áreas e nações, bem como com a localização de alguns ramos de negócios em certas regiões específicas. A vantagem é oriunda da rotação no mercado de trabalho, da disponibilidade de serviços de baixo custo e externalidades tecnológicas ou spillovers. A evidência empírica mostrou que tais fenômenos podem ser observados em setores de alta ou baixa tecnologia.

Kogut (1991) examinou a noção de competitividade de países, uma vez que os países são diferentes em suas capacidades organizacionais e tecnológicas. Estas diferenças influenciam o desempenho das empresas baseadas nestes países. Parte da heterogeneidade observada neste desempenho pode ser atribuída ao país de origem da empresa. A persistência dessas diferenças competitivas entre países é função da relativa permeabilidade das fronteiras dos países versus as fronteiras das empresas. A menor taxa de difusão das capacidades organizacionais em relação às capacidades tecnológicas é uma razão adicional para a persistência dessas vantagens competitivas.

Michael Porter (1990, 1994, 1998, 2000) desenvolveu toda uma teoria da competição baseada em aglomerados. Os aglomerados afetam a competição de três maneiras amplas: eles aumentam a produtividade das empresas ou ramos de negócios constituintes; aumentam sua capacidade de inovação; e estimulam a formação de novos negócios que amparam a inovação e expandem o aglomerado (PORTER, 1998, p. 213). Essa abordagem do aglomerado oferece, portanto, uma influência dinâmica da localização em oposição a uma estática, associada com a análise econômica básica. Porter (1990) criou o modelo do “diamante”, para analisar os determinantes da vantagem competitiva das nações. O diamante consiste em quatro grupos de atributos inter-relacionados ligados à localização: condições de fatores (input); condições de demanda; setores relacionados e de apoio; e o contexto estratégico e de rivalidade, em que se insere a empresa.

O resumo acima, de forma alguma abrangente, mostra que as pesquisas anteriores e a teoria nas áreas da economia e estratégia apóiam a noção de que a localização afeta o desempenho das empresas. Parte da heterogeneidade do 
desempenho das empresas é atribuível, portanto, à localização. Os estudos anteriores sobre a composição da variância do desempenho, contudo, nunca consideraram este tipo de influência, talvez porque a maioria foi realizada com dados dos EUA apenas. Por outro lado, pesquisas específicas em aglomerados de empresas e setores analisaram aglomerações específicas e o desempenho das empresas que delas fazem parte, não integrando na análise os outros fatores que determinam o desempenho. $\mathrm{O}$ efeito país proposto neste artigo captura fatores específicos do país que afetam todas as empresas, em dado país, de forma semelhante. Isto engloba a maior parte do conceito proposto por Kogut (1991), mas apenas parte da influência dos aglomerados conforme estudado por Porter (1994). A influência dos aglomerados não é fácil de ser incluída, uma vez que envolve algumas empresas de certo ramo de negócios, mas não todas. Ele também envolve algumas empresas de ramos de negócios diferentes, mas relacionados e, finalmente, a definição geográfica pode não coincidir com as fronteiras nacionais. Empresas localizadas em países vizinhos podem fazer parte de um aglomerado. Parte desse efeito de aglomerado pode ser, contudo, capturado na interação do país com o ramo de negócios, mas deve ser reconhecido que esta não é a definição estrita de aglomerado.

\section{Método e Dados}

\section{Componentes da Variância}

A técnica de componentes de variância é amplamente usada em outros campos, como a genética, mas sua aplicação na área de negócios tem sido limitada (RUMELT, 1991). Ela tenta decompor a variância observada em uma variável específica em componentes, ou variâncias que representam a contribuição de cada efeito aleatório que esteja causando essa variância final. Searle, Casella e McCulloch (1992) forneceram tratamento abrangente da técnica. No caso em estudo, empresa, ramo de negócios, ano e país são tomados como efeitos aleatórios, cada qual contribuindo para a variância total da variável observável. Eis o modelo básico, sem considerar possíveis interações:

$r_{i, j, k, t}=\mu+\gamma_{t}+\alpha_{i}+\beta_{j}+\phi_{k}+\varepsilon_{i, j, k, t}$

Onde $r_{i, j, k, t}$ é a medida de desempenho de uma empresa individual na amostra. $\mathrm{O}$ índice $t$ representa os diversos anos considerados; $i$ os diversos setores da indústria ou os ramos de negócios; $j$ o país onde a empresa está localizada; e $k$ as empresas individuais. $O$ termo $\mu$ é a média do resultado de todas as empresas consideradas como grupo. O termo $\gamma_{t}$ é o efeito do ano; $\alpha_{i}$ é o efeito do ramo de 
negócios; $\beta_{j}$ responde pelo efeito do país; finalmente, $\phi_{k}$ representa da contribuição individual da empresa $k$ aos seus resultados, ou o efeito da empresa. O termo de erro $\varepsilon_{l, \varphi, \kappa, \tau t}$ é o resíduo, não explicado pelo modelo. Este modelo simples pode ser ampliado, incluindo as possíveis interações do país com o ramo de negócios e ano, acrescentando outros três termos que respondem pelas interações paísramo, país-ano e ramo-ano.

A variância do termo $r_{i, j, k, t}$ é dada por:

$\sigma_{r}^{2}=\sigma_{\gamma}^{2}+\sigma_{\alpha}^{2}+\sigma_{\beta}^{2}+\sigma_{\phi}^{2}+\sigma_{\varepsilon}^{2}$

Essas variâncias podem ser estimadas por vários métodos. Este trabalho usa a estimativa MINQUE (Minimum Norm Quadratic Estimation), que é reconhecida como não tendo viés e não requer nenhuma interação, reduzindo a necessidade de potência computacional.

\section{Mensuração do Desempenho}

Uma questão importante neste tipo de análise é como medir o desempenho da empresa? O desempenho tem sido visto, geralmente, como tendo uma natureza multidimensional, relativa aos vários stakeholders envolvidos e não podendo ser representado por um único índice (CHAKRAVARTHY, 1986; DONALDSON; PRESTON, 1995; KAPLAN; NORTON, 1996, p. 24). Além disso, uma verdadeira medida de desempenho estratégico deveria incluir um componente futurístico relativo à capacidade da empresa em enfrentar desafios futuros (CHAKRAVARTHY, 1986). Jensen (2001) questionou esta abordagem multidimensional, defendendo uma função de valor único, que incorpore todas as dimensões. Os indicadores financeiros acabam sendo usados, uma vez que estão disponíveis e são comparáveis; porém é necessário ter em mente que somente uma dimensão limitada de desempenho está sendo medida. A maioria dos estudos anteriores da composição da variância do desempenho usou a razão entre lucro contábil e os ativos totais da empresa. Alguns autores, no entanto, exploraram outras medidas financeiras como o $q$ de Tobin, lucro econômico, valor de mercado, medidas híbridas e mesmo pesquisas entre os gerentes, chegando a conclusões similares (HAWAWINI, SUBRAMANIAN; VERDIN, 2003; MCGAHAN, 1999; POWELL, 1996; WERNERFELT; MONTGOMERY, 1988). Reconhecendo todas essas limitações, esta pesquisa usou o retorno sobre os ativos como medida de desempenho. Foi usada a definição de retorno sobre os ativos da base de dados Compustat Global, que é calculada como a receita antes dos itens extraordinários divididos pela média dos ativos totais dos dois últimos anos. 


\section{Dados}

A base de dados COMPUSTAT Global foi a fonte de dados. Esta base de dados compila os dados financeiros e de mercado de mais de 13.000 empresas em mais de 80 países em todo o mundo. Os dados COMPUSTAT Global são coletados pela Standard \& Poor's, usando conjuntos consistentes de itens de dados financeiros, que são desenvolvidos com base no exame das demonstrações financeiras das empresas. Os dados são normalizados de acordo com os princípios contábeis locais, métodos de divulgação e definições de itens de dados. Algumas empresas multinacionais relatam seus resultados em seus países de origem em vez do país onde as operações estão sendo realizadas. Este estudo está considerando esta definição de país, ou seja, o país onde os resultados são reportados. Outra limitação é que a base de dados COMPUSTAT Global não fornece uma discriminação das atividades da empresa por unidade de negócio. Um código de quatro dígitos SIC (Standard Industry Classification) é atribuído a cada empresa, considerando sua atividade mais típica. Isto provavelmente leva a uma subestimação do efeito indústria ou ramo de negócios. Na análise, foram incluídas somente as empresas com receitas e ativos totais de mais de 10 milhões de dólares americanos, e com resultados relatados em pelo menos quatro dos cinco anos considerados (1997-2001). No total, 12.592 empresas atenderam a esses critérios, fornecendo 60.092 observações, cobrindo 78 países e 448 códigos SIC de quatro dígitos. A análise foi feita agrupando os códigos SIC por amplos setores econômicos ou divisões. A Divisão A incluiu Agricultura, Silvicultura e Pesca (códigos SIC abaixo de 1000); a divisão B foi Mineração (códigos SIC 1000-1499); a divisão C foi Construção (códigos SIC 1500-1799); a divisão D, a maior delas, foi Manufatura (códigos SIC 2000-3999); a divisão E cobriu os Serviços de Transporte, Comunicações, Elétrico, Gás e Sanitário (códigos SIC 4000-4971); as divisões F e G foram analisadas juntamente, cobrindo o setor de Comércio Atacadista e Varejista (SIC 5000-5999); a divisão H cobriu os setores de Finanças, Seguro e de Imóveis (SIC 6000-6799); a divisão I cobriu o setor de Serviços (SIC 7000-8999).

\section{Resultados e Discussão}

A análise descritiva da amostra considerada, cobrindo 78 países, oferece uma perspectiva interessante das características da distribuição de desempenho medido como retorno sobre os ativos. A estimativa da média foi de 1,71\% e do desviopadrão de 13,72\%. Este valor de desvio-padrão é comparável aos estudos anteriores feitos somente nos dados dos Estados Unidos. McGahan e Porter (1997) encontraram um desvio-padrão de 15,7\% e Rumelt (1991) de 16,7\%. É 
importante observar a relevância desta dispersão, relacionando-a com a interpretação gerencial do resultado para uma empresa individual. Uma empresa que estiver somente um desvio-padrão acima da média apresenta resultados muito bons e uma empresa situada em desvio-padrão abaixo da média está apresentando desempenho realmente fraco e preocupante. Outro aspecto é a forma da distribuição que pode ser vista na Figura 1. Trata-se de distribuição em forma de sino, ligeiramente assimétrica para a direita (coeficiente de assimetria de -7,86) e significativamente mais pontuda do que a distribuição normal. Tratase de característica leptocúrtica, indicada pelo alto coeficiente de curtose de 176,14. Intuitivamente, esta distribuição representa uma situação na qual as laterais da curva normal foram desbastadas e este material foi acrescentado ao topo e às caudas (SPANOS, 1999). As empresas tendem a agrupar seus resultados em torno da média, de forma mais próxima do que se poderia esperar, numa distribuição normal e, ao mesmo tempo, mostram grandes desvios mais freqüentes (positivos e negativos) da média do que se poderia esperar, se a distribuição fosse normal. A Tabela 1 mostra os resultados descritivos para cada setor econômico ou divisão.

\section{Figura 1: Histograma da Distribuição dos Resultados de Desempenho}

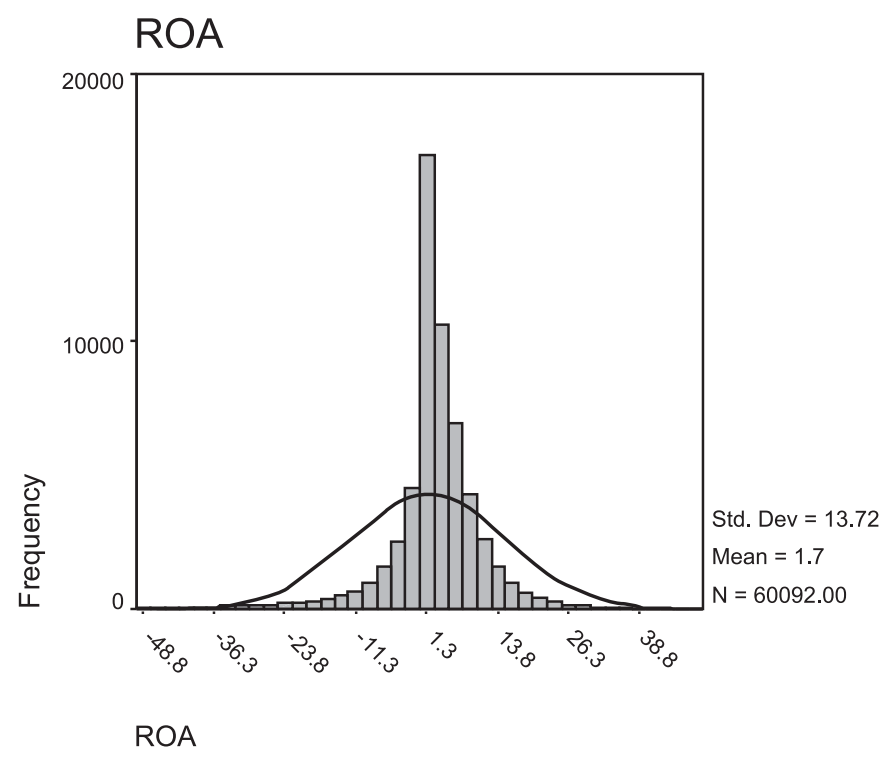

Fonte: dados da pesquisa. 


\section{Tabela 1: Análise Descritiva da Amostra por Setor Econômico}

\begin{tabular}{|l|c|c|c|c|c|c|c|c|}
\hline Setor Econômico & $\begin{array}{c}\text { Obser- } \\
\text { vações }\end{array}$ & $\begin{array}{c}\text { Empre- } \\
\text { sas }\end{array}$ & Países & $\begin{array}{c}\text { Setores } \\
\text { Industriais }\end{array}$ & Média & $\begin{array}{c}\text { Va- } \\
\text { riância }\end{array}$ & $\begin{array}{c}\text { Assi- } \\
\text { metria }\end{array}$ & Curtose \\
\hline $\begin{array}{l}\text { Agricultura, } \\
\text { Silvicultura e } \\
\text { Pesca }\end{array}$ & 400 & 88 & 24 & 5 & 1.66 & 83,96 & $-2,07$ & 8,26 \\
\hline Mineração & 1594 & 351 & 47 & 11 & 2,01 & 237,37 & $-2,57$ & 15,25 \\
\hline Construção & 2446 & 516 & 39 & 8 & 0,92 & 84,22 & $-2,56$ & 102,17 \\
\hline Manufatura & 27928 & 5940 & 61 & 223 & 2,05 & 173,11 & $-9,157$ & 263,98 \\
\hline Transporte & 5368 & 1141 & 56 & 37 & 1,59 & 180,26 & $-10,14$ & 203,63 \\
\hline Atacado e Varejo & 7493 & 1573 & 47 & 63 & 2,48 & 91,08 & $-3,27$ & 30,65 \\
\hline $\begin{array}{l}\text { Seguro, Finanças } \\
\text { e Imóveis }\end{array}$ & 8128 & 1816 & 62 & 40 & 1,99 & 85,95 & $-3,53$ & 97,89 \\
\hline Serviços & 6735 & 1167 & 44 & 61 & $-0,6$ & 509,26 & $-5,39$ & 56,93 \\
\hline Total & 60092 & 12592 & 78 & 448 & 1,71 & 188,18 & $-7,86$ & 176,14 \\
\hline
\end{tabular}

Fonte: análise pelos autores com base na base de dados Compustat global.

A análise dos componentes da variância foi feita para cada setor econômico e os resultados apresentaram grandes variações na composição da variância, confirmando a constatação de McGahan e Porter (1997), ao analisar somente os dados dos EUA. A Tabela 2 mostra a composição da variância de cada setor econômico, usando um modelo simples no qual não se considerou a interação dos efeitos.

Tabela 2: Composição da Variância, Modelo Simples

\begin{tabular}{|l|c|c|c|c|c|c|c|c|}
\hline & $\begin{array}{c}\text { Agricul- } \\
\text { tura }\end{array}$ & $\begin{array}{c}\text { Mine- } \\
\text { ração }\end{array}$ & $\begin{array}{c}\text { Cons- } \\
\text { trução }\end{array}$ & $\begin{array}{c}\text { Manu- } \\
\text { fatura }\end{array}$ & $\begin{array}{c}\text { Trans- } \\
\text { porte }\end{array}$ & $\begin{array}{c}\text { Atacado e } \\
\text { Varejo }\end{array}$ & $\begin{array}{c}\text { Seguro, } \\
\text { Finanças e } \\
\text { Imóveis }\end{array}$ & Serviços \\
\hline Empresa & $27,7 \%$ & $14,0 \%$ & $6,5 \%$ & $37,2 \%$ & $49,5 \%$ & $42,6 \%$ & $40,4 \%$ & $43,3 \%$ \\
\hline País & $20,8 \%$ & $8,2 \%$ & $16,9 \%$ & $2,0 \%$ & $0,0 \%$ & $5,0 \%$ & $2,9 \%$ & $0,0 \%$ \\
\hline $\begin{array}{l}\text { Ramo de } \\
\text { negócios }\end{array}$ & $0,0 \%$ & $15,6 \%$ & $0,5 \%$ & $3,2 \%$ & $15,6 \%$ & $0,7 \%$ & $6,8 \%$ & $0,8 \%$ \\
\hline Ano & $0,6 \%$ & $2,9 \%$ & $0,2 \%$ & $1,2 \%$ & $0,4 \%$ & $0,8 \%$ & $0,2 \%$ & $2,5 \%$ \\
\hline Erro & $50,9 \%$ & $59,4 \%$ & $75,8 \%$ & $56,5 \%$ & $34,5 \%$ & $50,8 \%$ & $49,7 \%$ & $53,4 \%$ \\
\hline Total & $100 \%$ & $100 \%$ & $100 \%$ & $100 \%$ & $100 \%$ & $100 \%$ & $100 \%$ & $100 \%$ \\
\hline
\end{tabular}

Fonte: análise dos autores.

Na maioria dos casos, o modelo simples explica de 40 a 50\% da variância total, o que é consistente com os estudos anteriores revisados. O efeito da empresa individual foi o mais importante na maioria dos setores econômicos, com exceção de Construção e Mineração, em que foi o segundo fator mais influente. O efeito indústria ou ramo de negócios variou de zero a 15,6\% na Mineração e no Transporte. Foi surpreendentemente baixo na maioria dos setores econômicos, quando comparado com os estudos anteriores. O efeito ano esteve sempre abaixo de $3 \%$, consistentemente com todos os estudos anteriores. O efeito país foi 
detectado e mostrou variação não-sistemática nos diversos setores econômicos, variando de não-existente a 20,8\% na Agricultura.

O setor econômico manufatura contém o maior número de observações e foi também o mais explorado nas pesquisas anteriores. Merece análise mais completa. O desvio-padrão foi de 13,2\%, valor não muito diferente dos valores encontrados anteriormente: 18,7\% por Schmalensee (1985); 16,7\% por Rumelt (1991); e 15,7\% por McGahan e Porter (1997). O efeito empresa, que explicou $37,2 \%$ da variância total, também foi consistente com os 46,37\% de Rumelt (1991), e os 35,45\% de McGahan e Porter (1997). O efeito ramo de negócios de somente 3,2\%, no entanto, foi inferior aos 10,81\% encontrados por McGahan e Porter (1997). A comparação com o modelo de Rumelt (1991) não pôde ser feita adequadamente, pois ele usou um modelo que incluiu a interação ano $\mathrm{x}$ indústria, mas o valor foi claramente menor. Rumelt (1991) encontrou um efeito da indústria fixo de 8,32\% e um transitório (a interação com o ano) de 7,84\%. Uma possível explicação para esta diferença seria o fato de a amostra incluir empresas americanas e não-americanas, e os estudos anteriores foram feitos somente com dados dos EUA. A composição da variância fora dos Estados Unidos poderia ser diferente. Isto foi verificado, realizando a análise separadamente para os países americanos e não-americanos, porém os resultados não mostraram diferenças significativas para as duas subamostras. Outra explicação possível poderiam ser os períodos diferentes de coleta das amostras e a ocorrência de uma alteração na composição da variância com tempo. McNamara, Vaaler e Devers (2003) apresentaram uma análise que mostra a composição da variância em 17 janelas de quatro anos de 1978 a 1997, usando a base de dados Compustat americana. O efeito da indústria mostrou padrão claro e constante de redução, desde seu pico, em 1983-1986 de 13,1\%, a 3,5\% para a última janela analisada, 1994-1997. Claver, Molina e Tari (2002), usando modelo similar ao de Rumelt (1991), analisaram empresas espanholas no período 1994-1998, tendo encontrado um efeito fixo da indústria de $2,06 \%$ e um transitório de 2,78\%. Sob esta perspectiva, o valor de 3,2\% para o período de 1998-2001 parece bem razoável. Outro aspecto que poderia explicar o percentual menor do efeito ramo de negócios é que a base de dados Compustat Global atribui o código SIC mais representativo a toda a empresa, enquanto os resultados das empresas americanas da base de dados são divididos por linhas de negócios relatadas separadamente. Isto leva a uma combinação dos resultados que poderia reduzir o efeito do ramo de negócios em empresas diversificadas. O efeito país, no caso da manufatura, foi de apenas 2,0\% da variância total.

O efeito país foi maior nos setores econômicos de Agricultura e de Construção, respondendo por 20,8\% e 16,9\% da variância total. No setor de Mineração 
também atingiu 8,2\%. Isto não é surpreendente, uma vez que em todos esses setores econômicos os aspectos geográficos poderiam ter influência importante nos fatores de produção.

O modelo com interação, mostrado na Tabela 3, associou porcentagens relevantes da variância total à interação país x ramo de negócios para esses três setores econômicos. Isto indica os efeitos dos países específicos em ramos de negócios específicos e poderiam ser considerados como indicação imperfeita de um tipo de "efeito aglomeração industrial ou efeito cluster". De fato, a definição de aglomerado industrial ou cluster é mais específica, uma vez que não necessita incluir todas as empresas de dado setor industrial em um país; assim o fato de que uma parte da variância pode ser explicada por meio desta interação é altamente significativo.

\section{Tabela 3: Composição da Variância - Modelo com Interação País e Ramo de Negócios}

\begin{tabular}{|l|c|c|c|c|c|c|c|c|}
\hline & $\begin{array}{c}\text { Agricul- } \\
\text { tura }\end{array}$ & $\begin{array}{c}\text { Mine- } \\
\text { ração }\end{array}$ & $\begin{array}{c}\text { Cons- } \\
\text { trução }\end{array}$ & $\begin{array}{c}\text { Manufa- } \\
\text { tura }\end{array}$ & $\begin{array}{c}\text { Trans- } \\
\text { porte }\end{array}$ & $\begin{array}{c}\text { Atacado } \\
\text { e Varejo }\end{array}$ & $\begin{array}{c}\text { Seguro } \\
\text { Finanças e } \\
\text { Imóveis }\end{array}$ & Serviços \\
\hline Empresa & $26,3 \%$ & $11,9 \%$ & $2,4 \%$ & $40,9 \%$ & $23,6 \%$ & $33,8 \%$ & $28,1 \%$ & $45,6 \%$ \\
\hline País & $17,7 \%$ & $7,5 \%$ & $13,5 \%$ & $2,1 \%$ & $0,0 \%$ & $5,5 \%$ & $2,3 \%$ & $0,0 \%$ \\
\hline $\begin{array}{l}\text { Ramo de } \\
\text { negócios }\end{array}$ & $0,0 \%$ & $8,2 \%$ & $0,0 \%$ & $1,3 \%$ & $5,9 \%$ & $0,0 \%$ & $8,6 \%$ & $1,2 \%$ \\
\hline Ano & $0,6 \%$ & $3,0 \%$ & $0,2 \%$ & $1,1 \%$ & $0,3 \%$ & $0,8 \%$ & $0,2 \%$ & $2,4 \%$ \\
\hline $\begin{array}{l}\text { País x } \\
\text { ramo de } \\
\text { negócios }\end{array}$ & $4,5 \%$ & $7,5 \%$ & $11,7 \%$ & $0,0 \%$ & $45,0 \%$ & $12,2 \%$ & $19,0 \%$ & $0,0 \%$ \\
\hline Erro & $50,9 \%$ & $61,9 \%$ & $72,1 \%$ & $54,7 \%$ & $25,2 \%$ & $47,7 \%$ & $41,8 \%$ & $50,8 \%$ \\
\hline Total & $100 \%$ & $100 \%$ & $100 \%$ & $100 \%$ & $100 \%$ & $100 \%$ & $100 \%$ & $100 \%$ \\
\hline
\end{tabular}

Fonte: análise dos autores.

Os setores econômicos de Transporte, Atacado e Varejo, e Seguro, Finanças e Imóveis mostraram comportamento diferente. No modelo simples, o efeito empresa foi dominante com mais de $40 \%$ da variância total; o efeito país variou de zero para o setor de Transporte a 5,0\% para Atacado e Varejo; o efeito ramo de negócios variou de 0,7\% para o setor de Atacado e Varejo, a 15,6\% no Transporte. Isto é bem diferente do que foi encontrado por McGahan e Porter (1997), que encontraram um efeito ramo de negócios altamente significativo e efeito empresa bem pequeno para Transporte, Atacado e Varejo (Seguros, Finanças e Imóveis não foram analisados). Quando esses setores econômicos foram analisados com o modelo com interação, a interação país x ramo de negócios apresentou alto poder de explicação. No Transporte, a interação respondeu por 45,0\% da variância total, tornando-se o efeito dominante, uma vez que o efeito empresa caiu para 23,6\%. Um fenômeno similar, entretanto menos marcante, pôde ser visto nos setores de Atacado e Varejo; Seguro, Finanças e Imóveis. O 
desempenho das empresas, nesses setores econômicos, parece estar fortemente ligado a fatores associados ao país e ao ramo de negócios, deixando menos variância explicável pelos fatores idiossincráticos da empresa do que acontece em outros setores econômicos.

Finalmente, no setor de serviços, os efeitos país não apareceram nem no modelo simples nem no modelo com interação.

\section{Conclusões}

Esta pesquisa investigou a existência e a magnitude de um novo tipo de efeito na explicação do desempenho das empresas, usando análise dos componentes de variância. Seu principal achado foi que a localização é capaz de explicar parte da variância do desempenho observado entre as empresas, em diferentes setores econômicos e ramos de negócios, em todo o mundo. O país importa, e muito, quando se trata de explicar a dispersão do desempenho. Embora isto tenha sido indicado como fator importante na literatura econômica (KRUGMAN, 1994), explorado em vários estudos de caso na literatura estratégica (PORTER 1998, p. 197-287), ligado à competição em nível teórico (KOGUT, 1991; PORTER, 1998, p. 309-346), esta é a primeira avaliação estatística ampla desta influência, que cobriu 12.592 diferentes empresas em 78 países.

A natureza estatística e a grande base da amostra desta pesquisa também permitem uma avaliação da resposta à segunda pergunta natural: quanto o país importa? De forma geral, fatores associados com a empresa individual ainda são a fonte mais importante de explicação da dispersão do desempenho. O efeito país compete pelo segundo lugar com o efeito ramo de negócios. A composição da variância varia em diferentes setores econômicos. Os setores econômicos foram definidos como grupos amplos de indústrias ou ramos de negócios (códigos SIC de 4 dígitos) com algum tipo de similaridade como Mineração, Agricultura, Manufatura, e Varejo. McGahan e Porter (1997) também encontraram que a composição da variância é significativamente diferente entre os diversos setores econômicos. O país parece importar mais em setores econômicos em que os fatores de produção estejam logicamente associados à geografia, como Agricultura, Mineração e Construção. Na Agricultura, o efeito país pôde explicar 20,8\% da variância total observada. Na Construção, o efeito país constituiu o fator mais importante identificável com 16,9\% da variância total, superando os efeitos empresa. Na Mineração, o efeito país respondeu por 8,2\% da variância total, enquanto os efeitos ramo de negócios e empresa responderam por 15,6\% e 14,0\%, respectivamente. Na Manufatura, de longe o maior setor econômico 
considerado, englobando 223 ramos de negócios, e onde foi feita a maioria dos estudos anteriores, o efeito país respondeu por somente 2,0\% da variância total do desempenho. A Manufatura é dominada pelo efeito empresa, que pôde explicar $37,2 \%$ da variância total, enquanto o ramo de negócios respondeu por 3,2\%; e o efeito ano ficou com 1,2\% da variância total. Nos setores econômicos, em que a atividade está mais relacionada com o serviço e intangíveis (como Transporte, Atacado e Varejo, Finanças e Serviços), o país parece importar menos. No Atacado e Varejo, o país respondeu por 5,0\% da variância total e nas Finanças por 2,9\%; nos demais não se pôde identificar nenhum efeito relativo ao país.

A interação do país com o ramo de negócios também foi explorada, usando-se um modelo ampliado. A interação país x ramo de negócios está associada a condições específicas de certos países e certos ramos de negócios. Se as condições particulares de certo país afetam, positivamente ou negativamente, somente certos ramos específicos, este fator de interação captura tal variação. Isto certamente tem relação com o conceito de aglomerado industrial ou cluster. Se as empresas pertencentes ao ramo de calçados, na Itália, têm desempenho melhor do que as empresas de calçado em outras regiões do mundo, a contribuição desta diferença à variância total seria atribuível a este fator de interação. Dois aspectos devem ser considerados, na interpretação dos resultados desta interação e ao relacioná-los ao conceito de aglomerado industrial. O primeiro se relaciona com a extensão do fenômeno. Quando se detecta grande porcentagem de variância atribuída à interação, o fenômeno de interação deve acontecer muito freqüentemente na amostra de 78 países e 448 ramos de negócios. Se isto acontecer em somente alguns casos específicos, mesmo que possa ser muito importante quando acontece, somente pequena porcentagem da variância será explicada por meio do fator. O segundo aspecto relaciona-se com a definição de aglomerado. Um aglomerado ou cluster não é a interação direta do ramo de negócios com o país. Nem todas as empresas do mesmo ramo, em determinado país, precisam ser membros de aglomerado. $\mathrm{O}$ aglomerado pode ainda atravessar as fronteiras e incluir empresas dos países adjacentes. Além disso, o conceito de aglomerado inclui vários ramos de negócios com relações entre si. A interação de país e ramo de negócios captura, assim, somente parte do conceito de aglomerado. Qualquer porcentagem da variância total atribuível a ela deverá ser vista como altamente indicativa do efeito aglomerado.

Na manufatura, onde o próprio efeito país foi pequeno, a interação país x ramo não pôde ser detectada pelo modelo. Na Agricultura, Mineração e Construção a interação foi claramente perceptível, variando de 4,5\% na Agricultura a 11,7\% na Construção. A influência total do país pode ser estimada somando-se as porcentagens do país isoladamente com a interação país-ramo de negócios. Na Agricultura, esta soma chegou a 22,2\%, próximo do efeito empresa com $26,3 \%$; 
na Mineração e Construção o total representou o fator mais importante, explicando $15,0 \%$ e $25,2 \%$ da variância total respectivamente.

Nos setores econômicos de Transporte, Varejo e Finanças, em que o modelo simples detectou um efeito país pequeno ou não-existente, a introdução da interação produziu um resultado surpreendente. O modelo com interação revelou um efeito de interação significativo que foi capaz de explicar uma proporção relevante da variância total que não era capturada pelo modelo mais simples. No Transporte, a interação país x ramo de negócios conseguiu explicar 45,0\% da variância total contra $23,6 \%$ do efeito empresa. A variância total, explicada pelo modelo, que era de 49,2\% com o modelo simples, saltou para 74,8\% quando foi incluído o efeito interação. No Varejo e em Finanças a interação país-ramo também se mostrou relevante, com 12,2\% e 19,0\% respectivamente. Em Serviços não se detectou a interação de país e ramo de negócios.

Além da identificação e quantificação preliminar do efeito país e sua interação com o ramo de negócios, esta pesquisa ofereceu ainda a oportunidade de observar a composição da variância do desempenho fora dos EUA de modo amplo, pois essas análises se estenderam a 78 países. Em termos gerais, a análise indica que a variância desempenho no resto do mundo não é radicalmente diferente daquela encontrada com os dados dos EUA. O efeito empresa domina a explicação da variância do desempenho. Entretanto não foi possível confirmar a forte influência do ramo de negócios nos setores econômicos, fora da Manufatura, como foi encontrado por McGahan e Porter (1997), quando analisaram dados americanos. Em face das diferenças na amostra e método, isto indica a necessidade de pesquisa mais ampla na área para reconciliar e generalizar as descobertas.

Este trabalho também tem limitações. A amostra não pode ser considerada amostra probabilística de todas as empresas no mundo e, assim, a validade externa é limitada. No entanto, trata-se de amostra tão grande que os resultados são úteis, mesmo quando restritos à amostra, uma vez que as empresas mais relevantes de cada país fazem parte desta amostra. O conceito país também possui suas limitações. Na base de dados, país foi considerado como o país em que os resultados foram relatados. Assim, se uma empresa global decidiu consolidar seus resultados e relatá-los no país de origem, este será o país considerado no estudo. O grande número de empresas de 12.592 minimiza este problema que tem uma incidência muito pequena; mas o ponto deve ser reconhecido e pode ser explorado em estudos posteriores. A definição do ramo de negócios também padece de destino similar. Além das deficiências do sistema SIC em si, uma empresa diversificada, que opere em diversos setores, é considerada, na base COMPUSTAT Global, no ramo de negócios correspondente ao SIC mais típico. Uma análise futura possível, usando os dados para os EUA da base COMPUSTAT 
americana, onde ambas as formas de classificação estão disponíveis, poderia ser explorada. O aspecto dinâmico da composição da variância é outra possibilidade de extensão do estudo. Este trabalho analisou o período 1997-2001, pois o interesse era avaliar a situação atual, mas podem ser explorados diferentes espaços de tempo. A escolha de retorno sobre ativos como indicador de desempenho possui limitações bem conhecidas e outras dimensões e medidas podem ser investigadas. Um ponto por investigar em maior detalhe é o fato de não se ter encontrado efeito país, nem sua interação com o ramo de negócios para o setor econômico de Serviços. A forma como este setor econômico é constituído na classificação SIC pode ser uma das causas; uma possível investigação seria desmembrar este setor em subsetores para verificar se o fenômeno volta a repetir-se.

\section{Ligação com Outras Tradições Teóricas a Serem Exploradas}

Este trabalho concentrou-se em mostrar que além dos elementos específicos do ramo de negócios e da empresa, o país aparece como fonte relevante da variância de desempenho das empresas. Isto leva a um conjunto de questões que não estão normalmente presentes na discussão estratégica dos negócios. Essas questões incluem o entendimento de como e por que alguns países constituem ambiente de negócio mais favorável do que outros, permitindo que as empresas tenham desempenho consistentemente melhor. As respostas preliminares a essas perguntas podem ser encontradas na nova economia institucional (NORTH, 1992) e na economia do desenvolvimento (MEIER; STIGLITZ, 2001). A nova economia institucional desenvolve uma visão das relações econômicas que rompe parcialmente com as premissas econômicas neoclássicas. Ela concorda com os teóricos neoclássicos na questão fundamental: economia é construída essencialmente em torno da alocação racional de recursos escassos. Há, porém, uma abordagem divergente com relação à racionalidade e ao papel das instituições. A nova economia institucional desenvolve a noção de racionalidade limitada de Simon (1945), para postular que, devido a esta racionalidade limitada e ao fato de os tomadores de decisão serem instituições imperfeitas, idéias e ideologias importam. Os novos economistas institucionais argumentam que as instituições impõem restrições à interação humana para estruturar o comportamento econômico. As instituições econômicas são, nesta perspectiva, as 'regras do jogo' de uma sociedade, ou, em outras palavras, os mecanismos formais e informais que estruturam a vida social. $\mathrm{O}$ modo como as instituições evoluem, em cada país, afetam, provavelmente, o desempenho das empresas diretamente; a compreensão de como essas instituições são criadas e evoluem é vital para entender as diferenças entre países. Por outro lado, alguns 
desdobramentos recentes na Economia do Desenvolvimento podem fornecer outras perspectivas importantes sobre como lidar com a criação de estratégias de negócios em diferentes países. A primeira geração de economistas que estudou os processos econômicos de desenvolvimento criou modelos de alta complexidade matemática, visando a transformações estruturais na economia, a começar pelo envolvimento do governo como agente planejador e como catalisador do processo de mudança, incluindo os aspectos econômicos, sociais e institucionais. Esses modelos iniciais concentravam-se no crescimento real da renda per capita, levando em consideração que a população estava crescendo e que, em muitos desses países, o fenômeno inflacionário também era persistente. A conseqüência lógica desses modelos era que o acúmulo de capital era a primeira prioridade (SOLOW, 2000) e que o Estado era o agente-chave no processo de desenvolvimento. Entretanto uma segunda geração de economistas de desenvolvimento concentrou-se em nova idéia. O desenvolvimento econômico depende, essencialmente, de agentes produtivos individuais que, por meio de suas capacidades, valores e recursos se adaptam ativamente às condições locais para aumentar sua riqueza pessoal e a produtividade geral do sistema econômico (SEN, 1997). Essa perspectiva abre novas possibilidades de diálogo entre a economia e a gestão estratégica, com enfoque diferente, investigando como o capital humano, competências, recursos, empreendedorismo, instituições, desenvolvimento e prosperidade estão ligados no cenário nacional pluralístico.

Em um mundo no qual as diferenças entre ricos e pobres estão cada vez maiores, uma abordagem pluralística deverá ser uma prioridade na ordem do dia da pesquisa para a gestão estratégica nos próximos anos.

\section{Artigo recebido em 04.12.2003. Aprovado em 28.01.2004.}

\section{REFERÊNCIAS}

BRUSH, T. H.;

BROMILEY, P.;

HENDRICKX, $\mathrm{M}$.

The relative influence of industry and corporation on business segment performance: an alternative estimate. Strategic Management Journal, New Jersey, v. 20, n. 6, p. 519-547, June. 1999.
CARROLL, G R.

A sociological view on why firms differ. Strategic Management Journal, New Jersey, v. 14, n. 4, p. 237-249, May 1993.

CHAKRAVARTHY, B. S.

Measuring strategic performance. Strategic Management Journal, New Jersey, v. 7, n. 5, p. 437-458, Sept. 1986. 
CHANG, S.;

SINGH, $\mathrm{H}$.

Corporate and industry effects on business unit competitive position. Strategic Management Journal, New Jersey, v. 21, n. 7, p. 739-752, July 2000.

\section{CLAVER, E.;}

MOLINA, J.;

TARÍ, J.

Firm and industry effects on firm profitability: a Spanish empirical analysis. European Management Journal, Oxford, v. 20, n. 3, p. 321328, June 2002.

DONALDSON, T.;

PRESTON, L. E.

The stakeholder theory of the corporation: concepts, evidence, and implications. Academy of Management Review, New York, v. 20, n. 1, p. 65-91, Jan. 1995.

HANSEN, G. S.;

WERNERFELT, B.

Determinants of firm performance: The relative importance of economic and organizational factors. Strategic Management Journal, New Jersey, v. 10, n. 5, p. 399-411, Sept./Oct. 1989.

HAWAWINI, G.;

SUBRAMANIAN, V.;

VERDIN, P.

Is performance driven by industry - or firm-specific factors? A new look at the evidence. Strategic Management Journal, New Jersey, v. 24, n. 1, p. 116. Jan. 2003.

KAPLAN, R. S.;

NORTON, D. P.

The balanced scorecard: translating strategy into action. Boston, Harvard Business School Press, 1996. p. 21-40.
KOGUT, B.

Country capabilities and the permeability of borders. Strategic Management Journal, New Jersey, v. 12, n. 4, p. 33-47, Apr. 1991.

\section{KRUGMAN, P.}

Location and competition: notes on economic geography. In: RUMELT, R.; SCHENDEL, D. E.; TEECE, D. J. Fundamental issues in strategy - a research agenda. Boston, Harvard Business School Press, 1994.

\section{JENSEN, M. C.}

Value maximization, stakeholder theory, and the corporate objective function. European Financial Management, Oxford, v. 7, n. 3, p. 297317, Sept. 2001.

\section{MARCH, J. G.;}

SUTTON, R. I.

Organizational performance as a dependent variable. Organization Science, Maryland, Estados Unidos, v. 8, n. 6, p. 698-706, Nov./Dec. 1997.

MARSHALL, A.

Principles of Economics. 8th Edition, New York: The McMillan Company, 1952.

\section{MAURI, A. J.;}

MICHAELS, M. P.

Firm and industry effects within strategic management: An empirical examination. Strategic Management Journal, New Jersey, v. 19, n. 3, p. 211-219, Mar. 1998.

\section{McGAHAN, A. M.}

The performance of US corporations: 1981 - 1994. The Journal of Industrial Economics, Oxford, v. 47, n. 4, p. 373-398, Dec. 1999. 
McGAHAN, A. M.;

PORTER, M. E.

How much does industry matter, really? Strategic Management Journal, New Jersey, v. 18, n. 6, p. 1530, summer 1997.

The persistence of shocks to profitability. The Review of Economics and Statistics, Cambridge: Estados Unidos da América, v. 81, n. 1, p. 143-153, Feb. 1999.

What do we know about variance in accounting profitability? Management Science, Maryland: Estados Unidos da América, v. 48, n. 7, p. 834-851, July 2002.

McNAMARA, G.;

VAALER, P. M.;

DEVERS, C.

Same as it ever was: the search for evidence of increasing hypercompetition. Strategic Management Journal, New Jersey, v. 24, n. 3, p. 261-278, Mar. 2003.

\section{MEIER, G;}

STIGLITZ, J.

Frontiers of Development Economics - The Future in Perspective, Oxford, Oxford University Press-World Bank, 2001.

MONTGOMERY, C.A.;

PORTER, M. E.

Strategy: seeking and securing competitive advantage. Boston, Harvard Business School Publishing, 1991.

\section{NELSON, R. R.}

Why do firms differ, and how does it matter? Strategic Management Journal, New Jersey, v. 12, n. 8, p. 61-74, winter 1991.

\section{NORTH, D. C.}

Institutions and Economic Theory, The American Economist, Hattiesburg: Mississippi, v. 36, n. 1, p. 3-6, spring 1992.

\section{PORTER, $M$.}

Location, competition, and economic development: local cluster in a global economy. Economic Development Quarterly, Thousand Oaks: California, v. 14, n. 1, p. 15-34, Feb. 2000.

On competition. Boston, Harvard Business School Publishing, 1998. p. 197-287/309-346.

The competitive advantage of nations. New York, The Free Press, 1990.

The role of location on competition. Journal of the Economics of Business, London, v. 1, n. 1, p. 35-39, Mar. 1994.

POWELL, T. C.

How much does industry matter? An alternative empirical test. Strategic Management Journal, New Jersey, v. 17, n. 4, p. 323-334, Apr. 1996.

\section{RICARDO, D.}

Principles of Political Economy and Taxation. Amherst NY, Prometheus Books, 1996. 
ROQUEBERT, J.A.;

PHILLIPS, R. L.;

WESTFALL, P.A.

Markets vs. management: what drives profitability? Strategic Management Journal, New Jersey, v. 17, n. 8, p. 653-664, Oct. 1996.

\section{RUMELT, R. P.}

How much does industry matter? Strategic Management Journal, New Jersey, v. 12, n. 3, p. 167-185, Mar. 1991.

SCHMALENSEE, $\mathrm{R}$.

Do markets differ much? The American Economic Review, Nashville, v. 75, n. 3, p. 341-351, June 1985.

SEARLE, S. R.;

CASELLA, G.;

McCULLOCH, C. E.

Variance components. New York: John Wiley \& Sons Inc, 1992. p. 118/44-107.

SEN, A. K.

Resources, Values and Development. Cambridge MA: Harvard University Press, 1997.
SIMON, H.

Administrative Behavior. New York:

Free Press, 1945.

SMITH, A.

The Wealth of Nations. London:

Penguin Books, 2000.

SOLOW, R. M.

Growth Theory - An Exposition, Oxford: Oxford University Press, 2000.

\section{SPANOS, A.}

Probability theory and statistical inference: econometric modeling with observational data. Cambridge: Cambridge University Press, 1999.

WERNERFELT, B.;

\section{MONTGOMERY, C.A.}

Tobin's q and the importance of focus in firm performance. The American Economic Review, Nashville, v. 78, n. 1, p. 246-250, Mar. 1988. 